\title{
Sacred Texts and Symbols: An Indigenous Filipino Perspective on Reading
}

\author{
M. Elena Clariza, University of Hawai'i at Mānoa, USA
}

\begin{abstract}
Reading in the Philippines is a process whereby the body, mind and spirit are engaged. Even though Filipinos are predominantly Catholic, many believe that creative energy, in the form of spirits, dwells in nature. These spirits must be respected or else they can unleash their wrath through sickness and natural calamities. As a contribution to preserving Filipino indigenous knowledge, this paper will explore whatok, the tattooing tradition of the Butbut people of Kalinga and t'nalak, the weaving tradition of the T'boli people of Mindanao. The aim of this paper is to preserve the unique culture of the Philippines' indigenous peoples' while sharing a decolonized perspective on reading. The term "decolonized" is used to mean peeling away the layers of nearly 400 years of Spanish and American colonial influence on Filipino culture. I will do this by studying the ways in which indigenous Filipino people record memory. The Philippines has an ancient syllabary system, but I will focus on older forms of transmitting ancestral knowledge, tattooing and textile making. Hopefully, this method will challenge readers to see tattoos and textiles as a valid means of documentation beyond printed text.
\end{abstract}

Keywords: ancestral knowledge; body art; Filipino culture; indigenous reading; sacred text

Publication Type: special section publication

\section{Introduction}

$\mathrm{R}$ eading in the Philippines is a process that goes beyond printed text, where the body, mind and spirit are all simultaneously engaged. Although Filipinos are predominantly Catholic, many believe that creative energy, in the form of spirits, dwells in nature. The Philippines is located in the "Pacific Ring of Fire," an area in the Pacific Ocean Basin known for frequent earthquakes and volcanic eruptions. Filipinos depend on ancestral knowledge and the ability to rely on intuition to fully grasp and comprehend the effects and impacts of nature's cycles. A deep understanding of the environment and appropriate responses to its cycles are vital for the Filipinos' survival.

The Philippines is a culturally diverse country with over 7,000 islands and more than 150 languages (Reid, 2005). The term "Filipino," created during the Spanish colonial period (15211898), describes the national identity of people born and raised in the Philippines and also Filipinos living throughout the diaspora. Most Filipinos identify themselves by their ethnic identity or by the language that they speak. Regardless of the differences between the ethnic groups, most Filipinos share a common thread, usually present in their traditional practices. To contribute to the preservation of Filipino indigenous knowledge and practices, this paper will explore the tattooing tradition of whatok of the Butbut people of Kalinga and the weaving tradition of t'nalak, of the T'boli people of Mindanao.

The International Journal of Information, Diversity, \& Inclusion, 3(2), 2019

ISSN 2574-3430, jps.library.utoronto.ca/index.php/ijidi/index

DOI: $10.33137 /$ ijidi.v3i2.32593 
The aim of this paper is to pay tribute to the unique culture of the Philippines' indigenous peoples while sharing a decolonized perspective on reading. The term "decolonized" is used to mean peeling away the layers of nearly 400 years of Spanish and American colonial influence on Filipino culture. I will do this by studying the ways in which the indigenous people record memory. The Philippines has an ancient syllabary system, but I will focus on older forms of transmitting ancestral knowledge. Hopefully, this method will challenge readers to see tattoos and textiles as a valid means of documentation beyond printed text.

\section{Tattoos as a Cutaneous Bibliographic Archive}

In 1946, the Philippines re-gained its sovereignty from colonial powers. Since then, Filipino nationalists have been facing an upward battle in reclaiming their history and traditions, which were systematically degraded and silenced during the Spanish and American (1898-1946) colonial periods. For this reason, it is particularly useful to explore the traditions of the indigenous peoples to get a glimpse of the Filipino's ancient way of life.

The United Nations Development Program (UNDP) reports the existence of 14 to 17 million indigenous peoples in the Philippines belonging to 110 ethnolinguistic groups (UNDP, n.d.). Indigenous Filipinos were able to retain their culture by successfully resisting the advances of colonizers and fleeing deeper into the mountains. One of these groups is the Butbut people of the Kalinga region. They live in a landlocked area nestled in the heart of the Philippines' largest mountain range, the Cordillera, which is located in the north-central part of the Philippines (Krutek, \& Sugguiyao, 2010).

An important aspect of Butbut identity is whatok, a permanent body adornment or tattoo, which was once prevalent all over the Philippines (Wilcken, 2011). For example, the first Spanish explorers to the Philippines chronicled heavily tattooed people in the Visayas, the central islands of the Philippines, as early as 1521 (Wilcken, 2011). However, to the Butbut people, whatok tradition is much older. They trace its origin to the ullit (legends and stories), amamtun (riddles or proverbs), and excerpts from ullalim (epic stories) that are usually sung by a traditional tattoo practitioner, known as a manwhatok, during a tattoo session (Salvador-Amores, 2013).

Traditional tattooing has declined in Kalinga, but the region became a subject of international interest mainly because of a 101-year old indigenous woman named Whang-od Oggay of the Butbut ethnic tribe, who is referred to as the last and oldest traditional tattoo practitioner or manwhatok in Kalinga (Salvador-Amores, 2013). Tourists from around the world, including television crews from the Discovery Channel, have taken the arduous trek across the mountainous terrain seeking to obtain an authentic whatok from Whang-od (Catajan, 2016).

This surge of interest prompted Butbut elders to coin a new tattoo process called, emben a whatok, or invented tattoos for local and foreign tourists. Emben a whatok are portions of the traditional tattoos called whatok sa awi, or tattoos of the past, which are hand-tapped onto the skin of the elders (Salvador-Amores, 2013). These tattoos for tourists are for decorative purposes only.

Whang-od's ullalim tells the story of a tattooed hero named Banna from Lubo. He traversed rivers and mountains as a python to see the beautiful Lagkunawa of Tinglayan. Banna's most beautiful gift to Lagkunawa was the scales of a python skin magically embedded on her legs (Salvador-Amores, 2013). The combination of tattooing and storytelling connects its wearers to

The International Journal of Information, Diversity, \& Inclusion, 3(2), 2019

ISSN 2574-3430, jps.library.utoronto.ca/index.php/ijidi/index

DOI: $10.33137 /$ ijidi.v3i2.32593 
their ancestors and deities via the intertwined experience and expression of words, sounds, imagery, and text, all reflecting on the state of the body, mind, and spirit. To this end, Banna may appear as a protective deity (spirit) in the guise of a snakeskin (body), made powerful by incantations (sound and mind).

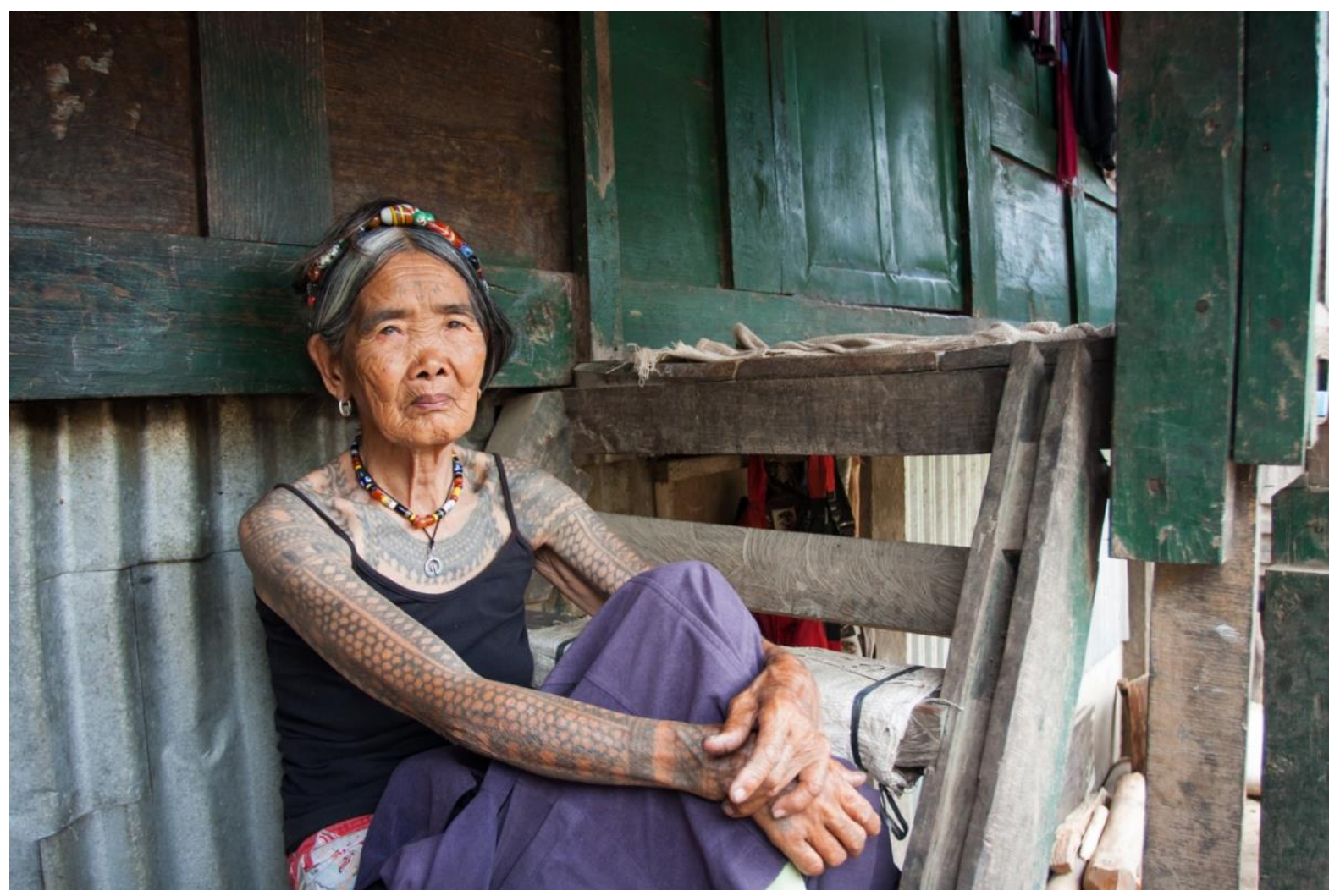

Figure 1. Whang-od in Buscalan, Philippines. Shutterstock. [Reproduced by permission].

How is whatok read? The different motifs are read using meanings that have been orally and physically passed down through generations. For example, one type of whatok motif chronicles the achievements of warriors. Salvador-Amores (2013) writes, "Lakay Wanawan, a renowned elder earned the only aiyung, a face mask of an owl, for his bravery and leading his tribe into battle. The tale of him single-handedly taking an enemy's chief's head that decided their victory lives on" (p. 161). Intricate markings may adorn other warriors, which may be likened to badges of honor for contemporary soldiers.

Others use whatok to chronicle personal and ancestral milestones, such as to record the year in which they first voted, to inscribe instructions for weaving, or to display the wealth of their elders (Salvador-Amores, 2013; Labrador, 2013). Whatok is commonly used to help the wearer remember experiences. Whang-od's tattoos always take her back to her past and elicit happy memories. In this sense, a whatok serves as a "cutaneous bodily archive" conveying the wearers' personal identities and documenting their biography (Salvador-Amores, 2013).

The International Journal of Information, Diversity, \& Inclusion, 3(2), 2019

ISSN 2574-3430, jps.library.utoronto.ca/index.php/ijidi/index

DOI: $10.33137 /$ ijidi.v3i2.32593 
Whatok's power is amplified through the unique stories of its wearer. For example, Whang-od has secret markings hidden on her arms bestowed on her by former lovers (Salvador-Amores, 2013). Her skin is also marked by the names and symbols of other tattoo practitioners to commemorate their meetings. To this day, Whang-od continues to transcribe new meanings to traditional motifs unique to her own experiences. The language of whatok evolves through time because of these improvisations. Whatok conveys a reading of experience and memory that becomes an ever-evolving text inscribed on the physical body as an ongoing narrative. It is meant to be read and interpreted iteratively, not only by the wearer but also by every person with whom the wearer interacts. In this way, whatok is a sacred text that commands respect for the person's essential humanity; for their presence, experiences, culture, and history. Whatok becomes a walking, breathing bibliographic archive of lived and historical experience, seen and unseen, and, as a living text, requires as much concern for its preservation as any print or digital manuscript.

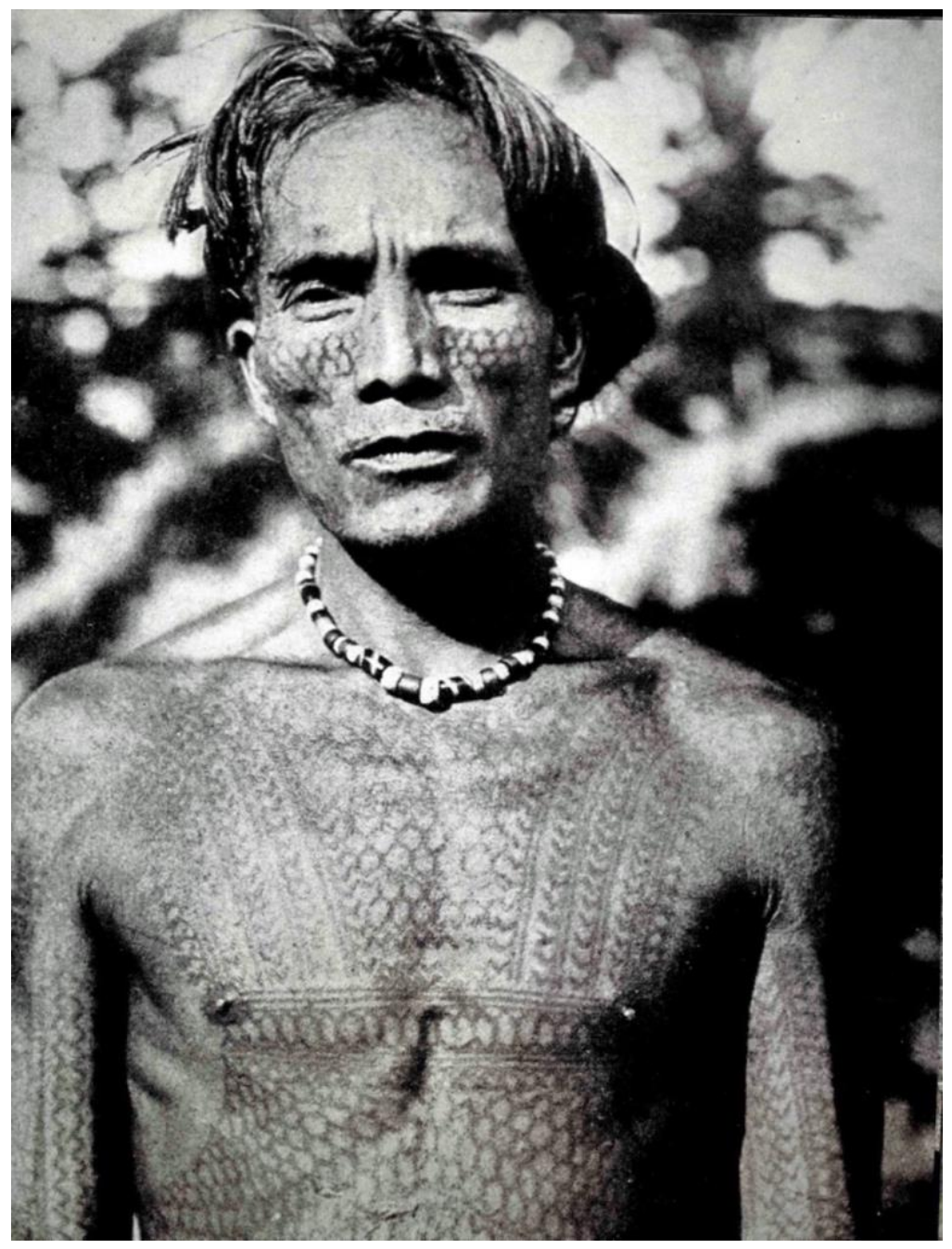

Figure 2. Lakay Wanawan. From: Worcester, 1912. [Image in the public domain].

The International Journal of Information, Diversity, \& Inclusion, 3(2), 2019

ISSN 2574-3430, jps.library.utoronto.ca/index.php/ijidi/index

DOI: $10.33137 /$ ijidi.v3i2.32593 


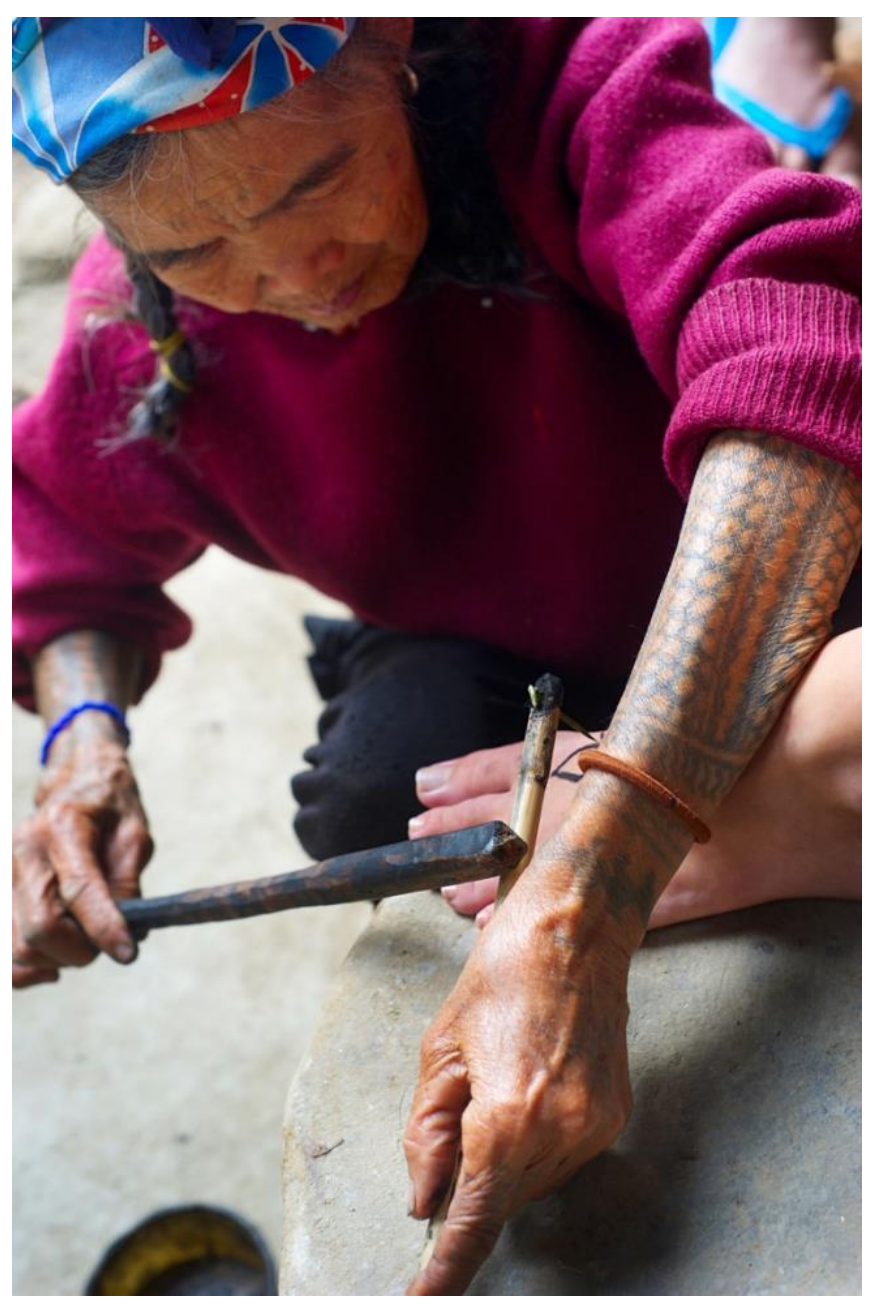

Figure 3. Wang-od tattooing a tourist using a citrus thorn. Shutterstock. [Reproduced by permission]

\section{T'nalak and the Language of Symbols}

Like the Butbut people of the Kalinga region, the T'boli of the Mindanao Island share the same reverence for nature as an interactive universe of elements (seen) and their spirits (the unseen) who live among the community members. The T'boli are renowned for their music and art, especially t'nalak. A t'nalak is a woven textile made of the whitest abaca, also known as Manila hemp, that has many traditional uses, such as paying a price for a bride, making a sacrifice to cure an illness, and serving as currency for bartering livestock, while the size of the of the cloth determines the number of inscribed horses or carabaos. The level of skill involved in creating t'nalak determines a weaver's status and position in the village (Paterno \& Oshima, 2001).

Every aspect of t'nalak preparation involves invoking Fu Dalu, the spirit of the abaca tree. An abaca plant will only be cut after a male T'boli recites a special prayer to Fu Dalu:

The International Journal of Information, Diversity, \& Inclusion, 3(2), 2019

ISSN 2574-3430, jps.library.utoronto.ca/index.php/ijidi/index

DOI: $10.33137 /$ ijidi.v3i2.32593 
Tenaba hu Fu Kedungon, Fu K'nalum, Fu Loko, ne Fu Dalu, I call on the spirit of abaca, them of K'nalum, the spirit of Loko, as well as Fu Dalu

Yom taha ye,

The owner of all things

Ani heyu nim t'nalak ni

We offer this knife to you

(bell or ring offerings are also made)

So you may ensure our success in the creation of t'nalak

Ne efet kol be kdengen

So that no illness will descend upon us,

until we have finished our task. (Castro, 2001)

What messages does t'nalak convey? Its commercial counterpart comes in different colors, but to the traditional weavers, the cloth can only be called " $t$ 'nalak" if it is in red, black and white (Repollo, 2018; Alvina, 2013). The dyes used are derived from plants found in their ancestral domain. The colors represent the resting places of souls after death (Alvina, 2013).

Red or hulo symbolizes the souls who died violently by the bullet or the blade. White or bukoy is for those who perished an untimely death or by their own hands. White also represents the color of the sky. Black or hitem is reserved for souls who passed away peacefully of natural causes. Even though tattoos are no longer common in contemporary T'boli life, they are important in afterlife. Designs depicting humans, frogs, or lizards tattooed on their hands and feet provide light in the total darkness of death (Alvina, 2013).

Weaving t'nalak requires mathematical skills in order to organize the fibers based on the patterns. The weaving process is ceremonial and adheres to many beliefs and warnings to avoid offending Fu Dalu. Castro (2013) confirms that

the weaver must never allow the fiber to touch the ground. Children must never play with the abaca fiber, neither must non-weavers ever touch the fibers, especially when these are already on the loom. Weavers must not shift place while completing a piece of cloth (p. 42).

It is only through complex and intricate processes like these that a t'nalak can be woven.

\section{Poetry in Woven Symbols}

The T'boli people live along the banks of Lake Sebu in a secluded and mountainous part of Mindanao, an island located in the southern part of the Philippines. It is a place where waterfalls abound and plants and animals thrive. This is where Fu Dalu gifts patterns to weavers in their dreams. Inas Cone of Lemkadi, born into a family of weavers, attributes her dream pattern of the kekem tree's branches to Fu Dalu. Subi Nalon, a weaver who first connected abaca fibers at five, dreamt of hafak menaul, a pattern that describes a wild eagle stretching its wings as it soars majestically through the sky (Paterno \& Oshima, 2001).

The International Journal of Information, Diversity, \& Inclusion, 3(2), 2019

ISSN 2574-3430, jps.library.utoronto.ca/index.php/ijidi/index

DOI: $10.33137 /$ ijidi.v3i2.32593 


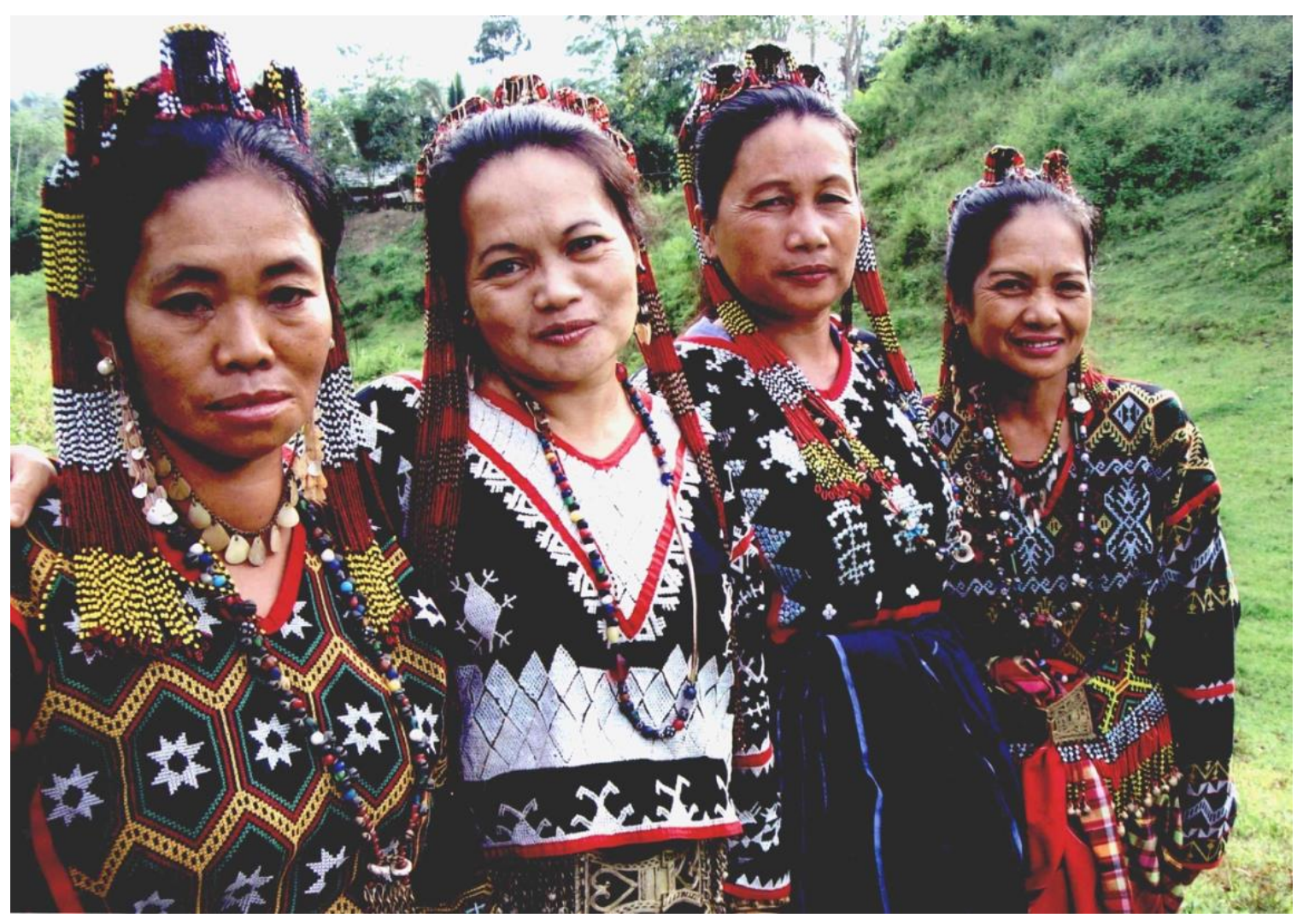

Figure 4. T'boli women of Lake Sebu in their traditional attire made of mother of pearls, plastic beads, copper and abaca fiber. From: Viacrusis, n.d. [Reproduced by permission].

The kekem tree grows abundantly around Lake Sebu. In the T'boli creation myth, the kekem is a stairway to heaven for good people. The villagers cut kekem in times of population decline to prevent souls from gaining access to the sky. The local villagers also rest in its roots when they fall ill because of the tree's healing properties (Paterno \& Oshima, 2001).

Just like whatok tattoos of the Butbut, t'nalak weaving tells the ancient stories of the T'boli people. In T'boli culture, weave patterns are passed matrilineally, from mother to daughter, via their dreams. As such, $t$ 'nalak weavers are known as "dream weavers" (Talavera, 2013). Indeed, Cone learned how to weave from her mother and her mother from her grandmother. Cone's only daughter, also a weaver, will keep the family's design depicting a bwengkel, a live crocodile, thus preserving over four generations of the family's foundation, heritage, symbology, and tradition (Paterno \& Oshima, 2001).

The bwengkel pattern tells of a cautionary tale of an illicit love affair between a man and a woman. As the story goes, one day as the lovers were courting, the woman dropped a pin into the ground. Water suddenly began to flow as she picked up the pin. Soon a small lake emerged and entrapped the couple. The lovers were cursed and transformed into crocodiles because they were relatives. The doomed couple is believed to still inhabit the lake to this day (Paterno \& Oshima, 2001). Such a pattern, coming through dreams, may convey a spiritual wisdom for a

The International Journal of Information, Diversity, \& Inclusion, 3(2), 2019

ISSN 2574-3430, jps.library.utoronto.ca/index.php/ijidi/index

DOI: $10.33137 /$ ijidi.v3i2.32593 
family that survives for generations.

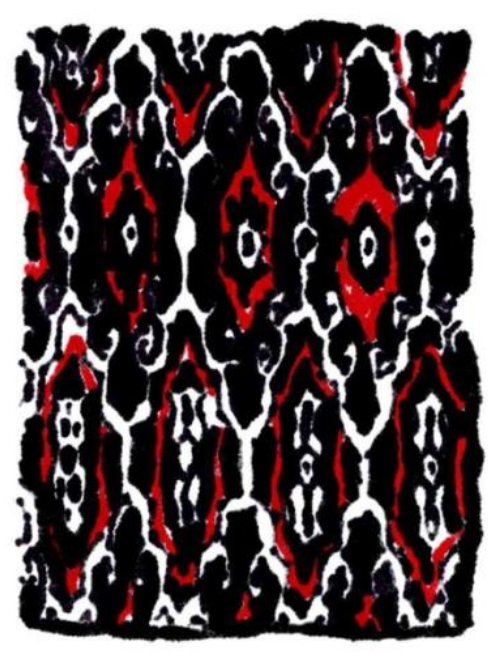

Figure 5. Kekem tree pattern derived from Neal Oshima's Bed kekem photograph. From Clariza, 2018. [Reproduced by permission]

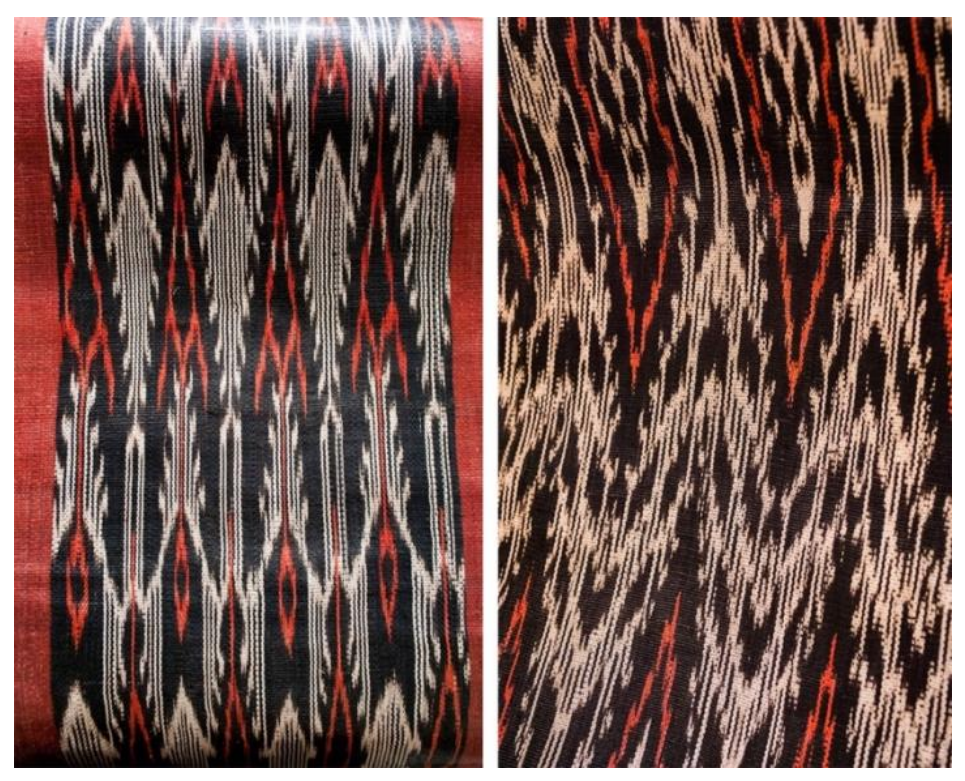

Figure 6. T'nalak cloth from the personal collection of Eva Washburn-Repollo. (Clariza 2018)

Like poets, t'nalak weavers use their loom to express the beauty that surrounds them. For example, the eben lobun pattern describes the formation of nimbus clouds heavy with rain. Eben also means a sling tied carefully to carry a baby as through in a cradle of clouds (Paterno \& Oshima, 2001, p. 128).

The International Journal of Information, Diversity, \& Inclusion, 3(2), 2019

ISSN 2574-3430, jps.library.utoronto.ca/index.php/ijidi/index

DOI: $10.33137 /$ ijidi.v3i2.32593 


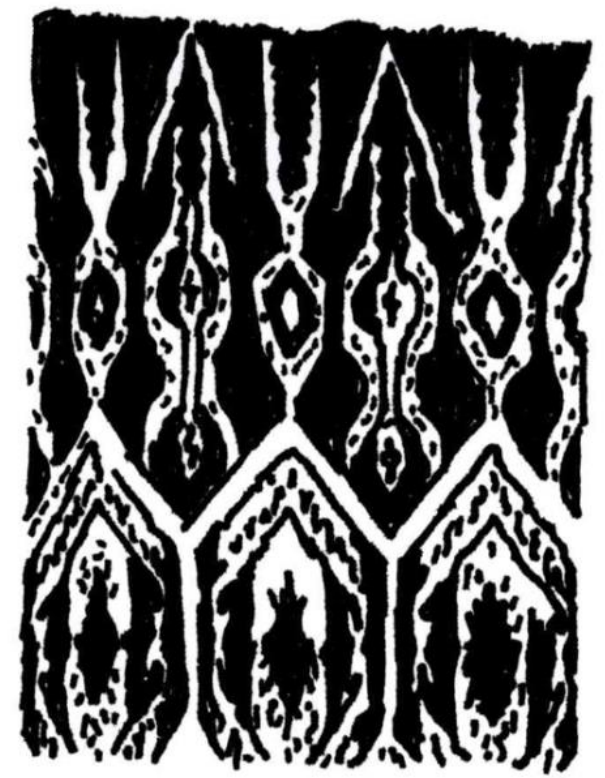

Figure 7. Bwengkel pattern derived from Neal Oshima's bed bwengkel photograph. From: Clariza, 2018. [Reproduced by permission].

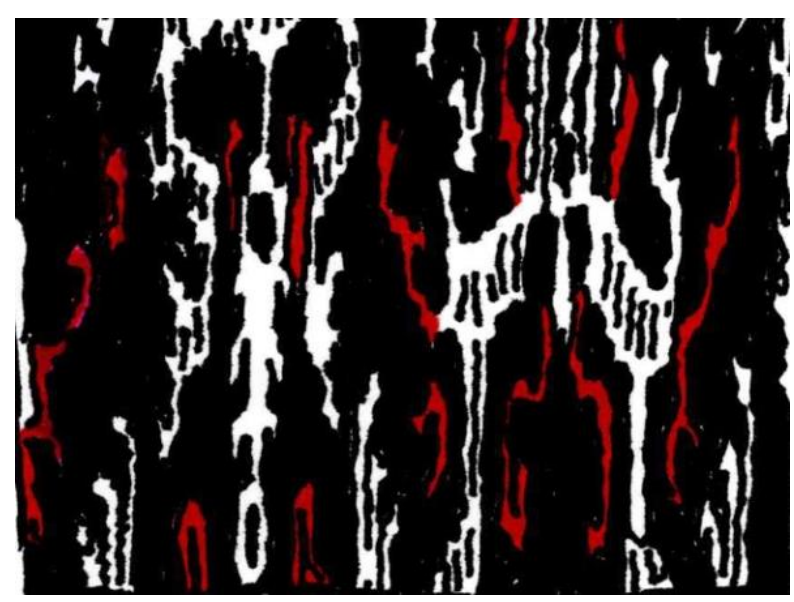

Figure 8. Eben Lobun pattern derived from Neal Oshima's eben lobun photograph. From: Clariza, 2018. [Reproduced by permission]

T'nalak can also speak of deep emotions and sorrow. In m'baga mugul by Yab Man, a daughter was left to finish her mother's design that was called the "dying weaver" (Paterno \& Oshima, 2001). Babara Ofung who feels the strong spirit of her aunt, a bo'i or leader, weaves about mugul, a pattern that appeared in her sister's dream. Mugul is the place where souls who perished naturally go. Sometimes weavers just need to vent like Nalon's Ketumbe Nungel. Her cloth communicates her vivid imagination. The pattern juxtaposes feeling of madness or nungel and soundness of mind (Paterno \& Oshima, 2001).

The International Journal of Information, Diversity, \& Inclusion, 3(2), 2019

ISSN 2574-3430, jps.library.utoronto.ca/index.php/ijidi/index

DOI: $10.33137 /$ ijidi.v3i2.32593 


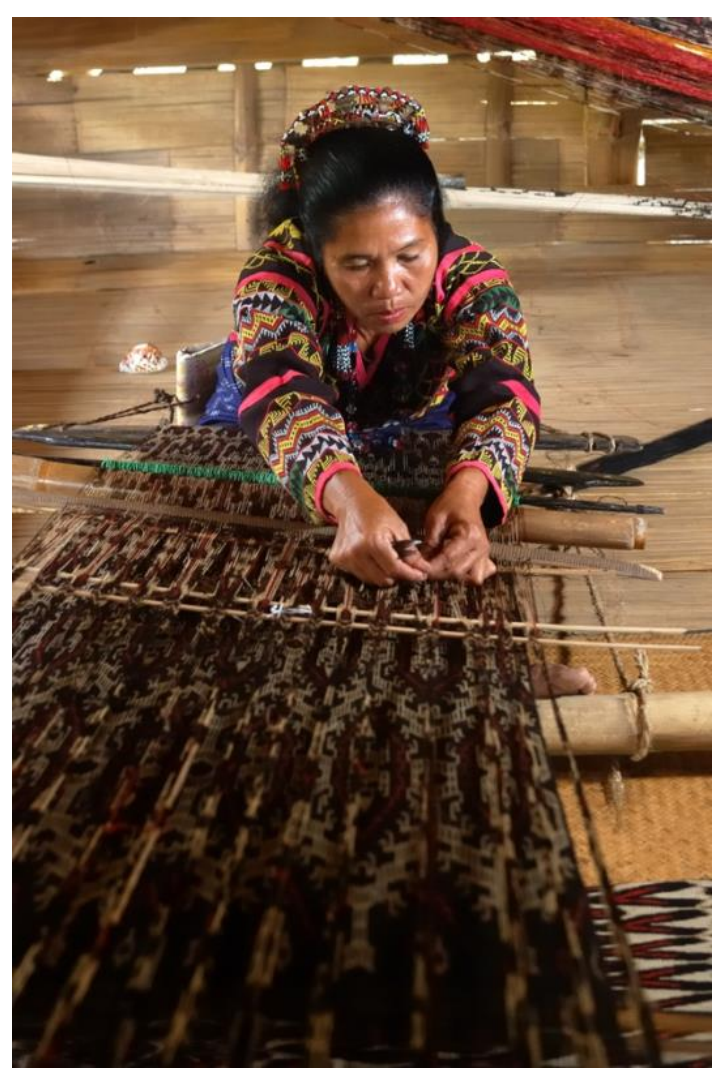

Figure 9. Barbara Ofung working on her loom. From: Barredo, 2009. [Image in the public domain]

\section{A Vanishing Culture}

Even though the T'boli people are active agents in the preservation of their traditions, t'nalak is also preserved in response to market demands. Similarly to the emben sa whatok, or invented tattoos, the mass produced t'nalak caters to the interests of both the tourist and the textile industry. This commercialization contributes to the disappearance of the textile's symbolic significance and ultimately chips away at the soul of the people who create them. Who will tell the stories of t'nalak dream weavers if/when t'nalak loses its original meaning because of commercialization? With market influences and non-indigenous interpretations of tradition, how will $t$ 'nalak be read, interpreted, and preserved?

Cultural objectification and appropriation hint at the darker tale of how the indigenous peoples of the Philippines have been mistreated on their own land. Whatok and t'nalak are more than artwork; yet, they have been commodified by the privileged locals and by tourists. These forms of preserving experiences and memory are records of a people's history and way of life, just as significant and legitimate as a book or a scroll. Losing them also means losing the Filipino collective history.

The preservation of indigenous knowledge requires restoring the stature and respect that the indigenous peoples once had but lost through the centuries of colonization. Indigenous Filipinos

The International Journal of Information, Diversity, \& Inclusion, 3(2), 2019

ISSN 2574-3430, jps.library.utoronto.ca/index.php/ijidi/index

DOI: $10.33137 /$ ijidi.v3i2.32593 
continue to struggle against discrimination, state-sponsored terrorism and loss of ancestral domain. For example, in December 2017, the Philippine military perpetrated the killings of eight members of the indigenous organization, T'boli-Manubo Sdaf Claimants Organization, after months of resistance against a coffee plantation expansion in their ancestral land (Paris, 2019). These are the issues connected to the Philippines' colonial past, which deserve a more in-depth follow up analysis.

To that end, Philippine Senator Loren Legarda, Chairperson of the Senate Committee on Finance, has spearheaded the Hibla ng Lahing Filipino: The Artistry of Philippine Textiles Traveling Exhibition in collaboration with the National Museum of the Philippines to attempt to raise awareness about indigenous cultural traditions. The exhibits, currently curated in the Philippines, encourage people's pride in local culture. They are accompanied by a week-long lecture series and feature weaving and embroidery demonstrations by indigenous masters. Hibla ng Lahing Filipino attempts to decolonize contemporary museum practices by centering its programming on the stories, history, and experiences of the people who create the materials and artifacts of the exhibits themselves.

The exhibit has also traveled all over Europe and North America, with plans of South American and Asian tours. The greatest impact, according to Dr. Ana Labrador, the Assistant Director or the National Museum of the Philippines, is the pride Hibla ng Lahing has given to some of the 10 million diasporic Filipinos across the world (Labrador, 2018). They are partly the driving force behind the resurgence of indigenous traditions in the Philippines as they come home searching for their Filipino identity.

In fact, Hamilton Library at the University of Hawai'i, in collaboration with the Hibla ng Lahing Filipino, University of Hawai'i Center for Philippine Studies and Philippine Consulate of Honolulu hosted the Piña-Seda: Pineapple and Silk Cloth from the Tropics Traveling Exhibition, September 17, 2018, - November 17, 2018. This collaboration touched the lives of over 400 participants within the first week of the project's opening. Many of the visitors were of Filipino descent with close ties to the Philippines. Students overwhelmingly reported feeling a closer connection to their ancestors and culture; they wanted to learn even more.

Programs that connect with larger initiatives like Hibla ng Lahing Filipino help promote respect for the culture and people behind the beautiful work. It is my dream that such efforts will continue to create a ripple effect across the Philippines and the world. Hopefully, if it has not been done yet, the rhetoric of cultural exchange will also include the protection of the indigenous peoples' human rights, especially in the context of authentic ways of life, worldviews, and cultural expression. Some of them are ancient, traditional indigenous practices, like whatok and t'nalak. Finally, there is hope that as long as elders are around, families, and communities will pass on indigenous tradition and foster social movements to support the local efforts of cultural respect and the preservation of artistic literacy practices.

\section{References}

Alvina, C. S. (2001). Colors and patterns of dreams. In Dreamweavers (pp. 46-58). Makati, PH: Bookmark.

The International Journal of Information, Diversity, \& Inclusion, 3(2), 2019

ISSN 2574-3430, jps.library.utoronto.ca/index.php/ijidi/index

DOI: $10.33137 /$ ijidi.v3i2.32593 
Arsie Pelanda, P. (2013). Portrait of elderly woman Filipina in Northern Luzon [Photograph]. Buscalan: Shutterstock.com (Originally photographed 2013)

Barredo, A. (2009). T'nalak weaving near Lake Sebu, Philippines [Photograph]. Lake Sebu: Flickr. (Originally photographed 2009)

Castro, S. (2001). Kedungon: The abaca fiber. In Dreamweavers (pp. 34-45). Makati, Philippines: Bookmark.

Catajan, M. E. ( 2016, October 5). Chasing Whang-od, the oldest Kalinga mambabatok. SunStar Philippines. Retrieved January 21, 2019, from https://www.sunstar.com.ph/article/102315/

Clariza, E. (2018). Bwengkel [Sketch].

Clariza, E. (2018). Eben Lobun [Sketch].

Clariza, E. (2018). Kekem tree [Sketch].

Clariza, E. (2018). T'nalak cloth [Photograph]. Honolulu (Originally photographed 2018).

Joyfull (2012). [Photograph]. Kalinga: Shutterstock.com (Originally photographed 2013).

Krutek, L. F., \& Sugguiyao, N. B. (2010). Kalinga tattoo: Ancient and modern expressions of the tribal. Germany: Edition Reuss.

Labrador, A. P. (2013). Hibla ng lahing filipino = The artistry of Philippine textiles. Manila, Philippines: National Museum of the Philippines.

Labrador, A. P. (2018, September 20). Decolonizing Museum Practice in the Philippines: Preventive Conservation and the National Museum of the Philippines. Lecture presented at Occasional Seminar, Center for Philippine Studies in University of Hawaii, Honolulu.

Oshima, N. (2001). Bed Bwengkel [Photograph]. In Dreamweavers (p. 109). Makati City: Bookmark. (Originally photographed 2001)

Oshima, N. (2001). Bed Kekem [Photograph]. In Dreamweavers (p. 102). Makati City: Bookmark. (Originally photographed 2001)

Oshima, N. (2001). Eben Lobun [Photograph]. In Dreamweavers (p. 128). Makati City: Bookmark. (Originally photographed 2001)

Oshima, N. (2001). M'baga Mugul [Photograph]. In Dreamweavers (p. 131). Makati City: Bookmark. (Originally photographed 2001)

Paris, J. (February 07, 2019). Human rights defenders killed under Duterte administration. Rappler. Retrieved April 25, 2019, from https: / / www.rappler.com/newsbreak/iq/222796-human-rights-defenders-killed-underduterte-administration

The International Journal of Information, Diversity, \& Inclusion, 3(2), 2019

ISSN 2574-3430, jps.library.utoronto.ca/index.php/ijidi/index

DOI: $10.33137 /$ ijidi.v3i2.32593 
Paterno, M. P., \& Oshima, N. M. (2001). Dreamweavers. Makati, Philippines: Bookmark.

Reid, L. A. (2005). Tagalog and Philippine languages. In P. Skutch (Ed.), Encyclopedia of Linguistics (pp. 3-4). New York, NY: Routledge.

Repollo, E. W. (2018, September 27). Multicolor Tinalak [Photograph]. Honolulu, HI: Eva Washburn Repollo Personal Collection.

Salvador-Amores, A. (2011). Batok (Traditional Tattoos) in diaspora: The reinvention of a globally mediated Kalinga identity. South East Asia Research,19(2), 293-318.

Salvador-Amores, A. (2013). Tapping ink, tattooing identities: Tradition and modernity in contemporary Kalinga society, North Luzon, Philippines. Diliman, Quezon City: The University of the Philippines.

Talavera, M. J. P. (2013, January). The T'boli: Songs, stories and society. n.p.: University of the Philippines. Retrieved from https://www.researchgate.net/publication/304347631_The_T'boli_Songs_Stories_and_ Society

United Nations Development Programme (n.d.). Fast facts: Indigenous peoples in the Philippines. Retrieved from http://www.ph.undp.org/content/philippines/en/home/library/democratic_governanc e/FastFacts-IPs.html

Viacrusis, I. (n.d.). T’boli women [Photograph]. Lake Sebu.

Wilcken, L. (2011). Filipino tattoos: Ancient to modern. Atlen, PA: Schiffer.

Worcester, D.C. (1912, September). Lakay Wanawan [Photograph]. In Headhunters of Northern Luzon (p. 859). National Geographic 23(9). (Originally photographed 1912).

M. Elena Clariza (mclariza@hawaii.edu) grew up in the Philippines and California and found her passion for social justice in both places. Clariza is a lifelong Philippine Studies scholar and currently the Philippine Studies Librarian at the University of Hawai'i at Mānoa (UHM). She was a community organizer for immigrant rights and environmental justice in California before coming to Hawai'i in 2003 to learn about non-violence education and organic farming. The calling to teach at a university was hard to ignore so Elena taught Conflict in the Asia-Pacific Region and Costumes and Cultures of South and Southeast Asia at UHM before becoming a fulltime librarian. She has a background in Education, Biology and Environmental Studies, Asian Studies, and Library and Information Science.

The International Journal of Information, Diversity, \& Inclusion, 3(2), 2019

ISSN 2574-3430, jps.library.utoronto.ca/index.php/ijidi/index

DOI: $10.33137 /$ ijidi.v3i2.32593 